\title{
Clonal variation of chromosome size derived from the rDNA cluster region in Candida albicans
}

\author{
Shin-IChi Iwaguchi, Michio Homma* and Kenji TanaKa
}

\begin{abstract}
Laboratory of Medical Mycology, Research Institute for Disease Mechanism and Control, Nagoya University School of Medicine, Showa-Ku, Nagoya 466, Japan
\end{abstract}

(Received 27 November 1991; revised 10 February 1992; accepted 26 February 1992)

\begin{abstract}
Of the eight Candida albicans chromosomes, chromosome 2, assigned by the MGL1 probe, is more variable in size than the other chromosomes among strains. We found that the clonal variation of chromosome 2 , which carries a rDNA gene, occurred at a frequency of up to $10 \%$ of the progeny clones. After total chromosomal digestion with $X h o I$, which has no recognition sites within the rDNA repeat unit, the fragments containing the rDNA cluster were detected by Southern hybridization. The difference in fragment sizes corresponded to the clonal size variation of chromosome 2. The intensity of hybridization with rDNA also correlated with the difference in size. In addition, there was no size change in the non-rDNA region as detected by NotI digestion of chromosome 2, and there was no observed change in the individual rDNA basic repeat unit size. From these lines of evidence, we confirmed that the clonal size variation of chromosome 2 which occurs at high frequency is derived from the size change of the rDNA cluster.
\end{abstract}

\section{Introduction}

Candida albicans is responsible for oral and vaginal candidiasis and sometimes causes severe systemic candidiasis in immunocompromized hosts (Odds, 1988). This organism does not have a sexual cycle and naturally exists in the asexual diploid state (Poulter et al., 1981; Riggsby et al., 1982). Accordingly, mutant isolation and genetic analysis in this organism are not trivial. However, recent developments in molecular genetic approaches, including electrophoretic karyotyping using pulsed-field gel electrophoresis (PFGE), have brought new information concerning the genome of $C$. albicans (for a recent review, see Scherer \& Magee, 1990). By this method, the haploid number has been determined to be eight (Iwaguchi et al., 1990; Lasker et al., 1989; Wickes et al., 1991). Chromosomal DNA bands separated by PFGE have been assigned using cloned DNAs of $C$. albicans or the homologous DNAs of Saccharomyces cerevisiae and a genetic map is being constructed (Scherer \& Magee, 1990).

Electrophoretic karyotype polymorphisms have been found between strains within a single species (Iwaguchi et al., 1990; Lott et al., 1987; Merz et al., 1988; Snell et al.,

\footnotetext{
* Author for correspondence. Tel. 0527412111 (ext. 2116); fax 052 7319479.

Abbreviations: PFGE, pulsed-field gel electrophoresis.
}

1987). This karyotyping method should be useful in clinical applications for strain identification (Merz, 1990). It has been reported that a change in karyotype appears to be correlated with a change in colony morphology (Rustchenko-Bulgac et al., 1990; Suzuki et al., 1989) although a definitive relationship between phenotype and karyotype has yet to be determined.

In our previous study, the chromosomal DNAs of C. albicans stock strains were resolved into 7-12 bands ranging in size from about $0.4 \mathrm{Mb}$ to about $3.0 \mathrm{Mb}$ (Iwaguchi et al., 1990). The separated bands were assigned to eight chromosomes based on hybridization patterns using eight different cloned DNA probes. The size of at least one homologue of seven out of eight chromosomes was found to be fairly well conserved. Thus, the karyotype polymorphism between strains was thought to be mainly derived from large size heterogeneity in one of the homologues (Iwaguchi et al., 1990). On the other hand, chromosome 2, assigned by the MGL1 probe, showed a marked degree of variation in both homologues. The underlying mechanism(s) for variation could be due to (i) deletion, (ii) amplification, (iii) translocation or (iv) unequal crossing-over. It has been suggested that these events occur at a high frequency in subtelomeric regions (Corcoran et al., 1988), rDNA regions (Szostak \& Wu, 1980), or transposon regions (Shapiro, 1983). 
Chromosome 2 is the most variable in size among strains isolated from patients (Iwaguchi et al., 1990). Strains isolated from individual patients after intervals of 1-6 months had different karyotypes, most of which were attributable to changes in chromosome 2 (Asakura et al., 1991). From these results, we assumed that chromosome 2 contains one or more regions responsible for chromosome rearrangement. Similar variable chromosomes have been observed in different groups (Rustchenko-Bulgac, 1991; Wickes et al., 1991). It has been shown that the variable chromosome carries a rDNA gene. It has also been demonstrated that a frequent chromosome size variation in Candida glabrata occurs in a chromosome carrying the rDNA gene (Asakura et al., 1991). However, it is not known how prevalent the phenomenon of chromosome size variation is, or whether it is due to some selective aspect of prolonged maintenance in culture. In this study, we first examine the frequency of the clonal size variation of chromosome 2 under vegetative growth, and second demonstrate that the size variation is derived from a size change in the rDNA cluster region of the progeny clones.

\section{Methods}

Strains. Isolates of C. albicans, TCH297, TCH298 and TCH300 were collected from 3 individual out-patients of the Obstetrics and Gynecology Department in Chita City Hospital, Japan, in 1989. The TCH strains were obtained from vaginas and were identified as C. albicans by their assimilation pattern with the API $20 \mathrm{C}$ system (Buesching et al., 1979), by serological testing with Candida check (Shinoda et al., 1981), and by chlamydospore formation. Strain FC18 was used as a reference strain.

Plasmids. The plasmids used in this study as probes in Southern hybridizations are listed in Table 1.

Preparation of yeast chromosome DNA for PFGE. The sample plug containing yeast chromosome DNA for PFGE was prepared by the method described previously (Iwaguchi et al., 1990).

$P F G E$. PFGE was carried out by the contour-clamped homogeneous electric fields (CHEF) method (Chu et al., 1986) using the Pulsaphor system with a hexagonal electrode array (Pharmacia-LKB). The yeast chromosome DNAs were separated in a $0.8 \%$ agarose gel usually with a $300 \mathrm{~s}$ switch time at $140 \mathrm{~V}$ for $24 \mathrm{~h}$ followed by a $1200 \mathrm{~s}$ switch time at $80 \mathrm{~V}$ for $48 \mathrm{~h}$ as described previously (Iwaguchi et al., 1990). $S$. cerevisiae (X2180-1 A; Mortimer \& Schild, 1985) and Schizosaccharomyces pombe (HM422 derived from 972h-; Fan et al., 1988) chromosomes were used as the size reference markers. The sizes of the chromosomes of Sch. pombe HM422 were estimated from the construction of a chromosome map; chromosome I is $5.7 \mathrm{Mb}$, chromosome II is $4.6 \mathrm{Mb}$ and chromosome III is $3.5 \mathrm{Mb}$ (Fan et al., 1988). In our previous report (Iwaguchi et al., 1990), we estimated the chromosome size of $C$. albicans by using a different reference strain. Thus, we have revised the size of the large bands in C. albicans as follows: the 2.86 and $2.66 \mathrm{Mb}$ chromosome bands of $\mathrm{FC} 18$ have been corrected to 3.5 and $3.18 \mathrm{Mb}$. $\lambda$ ladder concatemer DNA (Bio-Rad) and $\lambda$ DNA digested by EcoT14I (Takara) were also used as size markers.

Preparation of chromosome DNA probes for Southern hybridization. Chromosome DNAs of NUM46 were separated by PFGE in a $0.7 \%$ agarose gel and stained with $0.5 \mu \mathrm{g}$ ethidium bromide $\mathrm{ml}^{-1}$ for $1 \mathrm{~h}$ and destained with distilled water overnight. The chromosome 2 band was cut out with a razor blade under $365 \mathrm{~nm}$ UV light. The gel slice was transferred to a dialysis bag filled with $0.5 \times \mathrm{TBE}\left[1 \times \mathrm{TBE}\right.$ is $\left(\mathrm{g}^{-1}\right)$ : boric acid, 5.5; EDTA, 0.74; Tris, 10.8]. The electroelution was performed using field inversion gel electrophoresis (FIGE) in $0.5 \times$ TBE with a $16 \mathrm{~s}$ pulse forward and $8 \mathrm{~s} \mathrm{backward} \mathrm{for} 5 \mathrm{~h}$ at $6.7 \mathrm{~V} \mathrm{~cm}^{-1}$, and then for $2 \mathrm{~min}$ at $6.7 \mathrm{~V} \mathrm{~cm}^{-1}$ in the reverse direction to release the DNA from the wall of the dialysis bag. The DNA solution was treated once with an equal volume of phenol and then concentrated to $50 \mu 1$ with sec-butanol. The concentrated DNA solution was dialysed with $1 \mathrm{mM}$-EDTA/10 mM-Tris/ $\mathrm{HCl}(\mathrm{pH} \mathrm{8.0)}$ and used as a probe for Southern hybridization.

Southern hybridization. Southern hybridization was performed using the LYS2 probe, a rDNA probe, and the chromosome DNA probe using the method described previously (Iwaguchi et al., 1990). The intensity of the hybridization signals was measured with an image analyser system (BAS2000; Fuji). The signal intensity of the LYS2 probe was used as a reference to standardize the DNA concentration in each sample.

Restriction digestion of chromosome DNA in PFGE sample plugs. Sample plugs for PFGE were equilibrated in the appropriate reaction buffer $(200 \mu \mathrm{l})$ for restriction enzymes $X$ hoI or NotI for $30 \mathrm{~min}$ at room temperature. The plugs were transferred to fresh restriction buffer containing $\mathrm{Xhol}$ or NotI (20 units in $200 \mu \mathrm{l}$ ) and incubated overnight at $37^{\circ} \mathrm{C}$. The sample plugs were then washed once with $50 \mathrm{~mm}$-EDTA (pH 9.0) and the digested chromosome DNA in the plugs was separated by PFGE.

Restriction digest of chromosome 2 bands separated on PFGE. Chromosomes of TCH297, TCH298 and TCH300 were separated in a $0.7 \%$ agarose gel by PFGE, stained with ethidium bromide, and destained with distilled water. The chromosome 2 bands were cut out with a razor blade under $365 \mathrm{~nm}$ UV light. Ethidium bromide was immediately extracted with three washes of sec-butanol saturated with $1 \mathrm{M}-\mathrm{NaCl}, 1 \mathrm{~mm}-\mathrm{EDTA}$, and $10 \mathrm{~mm}-\mathrm{Tris} / \mathrm{HCl}(\mathrm{pH} 8 \cdot 0$ ), respectively, for $10 \mathrm{~min}$ each. The blocks were then equilibrated in $200 \mu \mathrm{l}$ of a restriction buffer for NotI, transferred into $200 \mu \mathrm{l}$ of fresh restriction buffer containing 20 units of Not I and incubated overnight at $37^{\circ} \mathrm{C}$. The digested DNA of chromosome 2 was separated by PFGE with a $100 \mathrm{~s}$ switch time at $180 \mathrm{~V}$ for $15 \mathrm{~h}$ followed by a $300 \mathrm{~s}$ switch time at $140 \mathrm{~V}$ for $20 \mathrm{~h}$.

Table 1. DNA probes for hybridization

\begin{tabular}{llll}
\hline \hline Probe & Plasmid & \multicolumn{1}{c}{ DNA fragment } & \multicolumn{1}{c}{ Source (references) } \\
\hline MGL1 & pYSK210 & $4.5 \mathrm{~kb}$ HindIII & J. A. Gorman (Iwaguchi et al., 1990; Magee et al., 1988) \\
LYS2 & pTK2-9-1 & $7.7 \mathrm{~kb}$ EcoRI & B. B. Magee (Iwaguchi et al., 1990; Magee et al., 1988) \\
rDNA & pAT68 & $10.8 \mathrm{~kb}$ Sall & A. Toh-e (Asakura et al., 1991; Sugihara et al., 1986) \\
BEN1 & pbenS10 & $0.9 \mathrm{~kb}$ Pst and EcoRI & J. A. Gorman (Iwaguchi et al., 1990; Magee et al., 1988) \\
pCHR7 & pCHR7 & $2.6 \mathrm{~kb}$ of BamHI and HindIII & B. B. Magee (Iwaguchi et al., 1990; Magee et al., 1988) \\
\hline \hline
\end{tabular}




\section{Results}

\section{Frequency of clonal size change in chromosome 2}

To examine the frequency of the size variation of chromosome 2, karyotypes were compared in five clones derived from each strain of TCH297, TCH298 or TCH300. Variation between the clones was observed in their karyotypes (Fig. 1 shows a part of the result). Four and three different karyotypes appeared in $\mathrm{TCH} 297$ and TCH298, respectively. On the other hand, clonal variation of karyotype was not observed in $\mathrm{TCH} 300$. The size difference of the chromosomal band in the karyotype amongst the clones was attributed to one or two large-sized bands. These bands were assigned as chromosome 2 by Southern hybridization using the MGL1 probe (data not shown) and the rDNA probe (Fig. 1b). The size change of chromosome 2 was observed in only one of the two homologues and the $3.1 \mathrm{Mb}$ chromosome 2 band was not changed amongst the clones. In a clone of TCH298-2, which was derived from $\mathrm{TCH} 298$, clonal variation was also observed in the size of chromosome 6 assigned by the LYS2 probe, in which the size difference was only $10 \mathrm{~kb}$ (Fig. 1, lane 6).

Next, three clones in each of the TCH strains, which are referred to as parental clones, were streaked on a YPD plate and 10 colonies were picked. These are referred to as progeny clones. The karyotype variation of the progeny clones was investigated. Fig. 2 shows the karyotypes of the parental and some of the progeny clones which were different from the parental karyotype. In one or two clones out of ten clones for each progeny group, the sizes of chromosome 2 bands were different from those of the parental clone. The size change of chromosome 2 was observed in $12 \%$ of all the progeny clones. Each of the parental colonies contained about $2 \times 10^{7}$ cells which were multiplied by 24.3 generations. It was calculated that the frequency of a detectable size change was about $5 \times 10^{-3}$ per cell division. In two out of 90 clones examined, TCH297-2-10 (data not shown) and 300-3-2 (Fig. 2, lane 10), the chromosomes which changed in size were not assigned by MGLl or an rDNA probe but by a BEN 1 probe as chromosome 7 and by a pCHR7 probe as chromosome 8 , respectively.

The size change of the rDNA cluster region among the clones

Since the size of chromosome 2 changed at high frequency and the rDNA gene is located on chromosome 2 , we examined the possibility that the size change of chromosome 2 amongst the strains was due to frequent DNA rearrangement in the rDNA region where the gene is highly repeated.
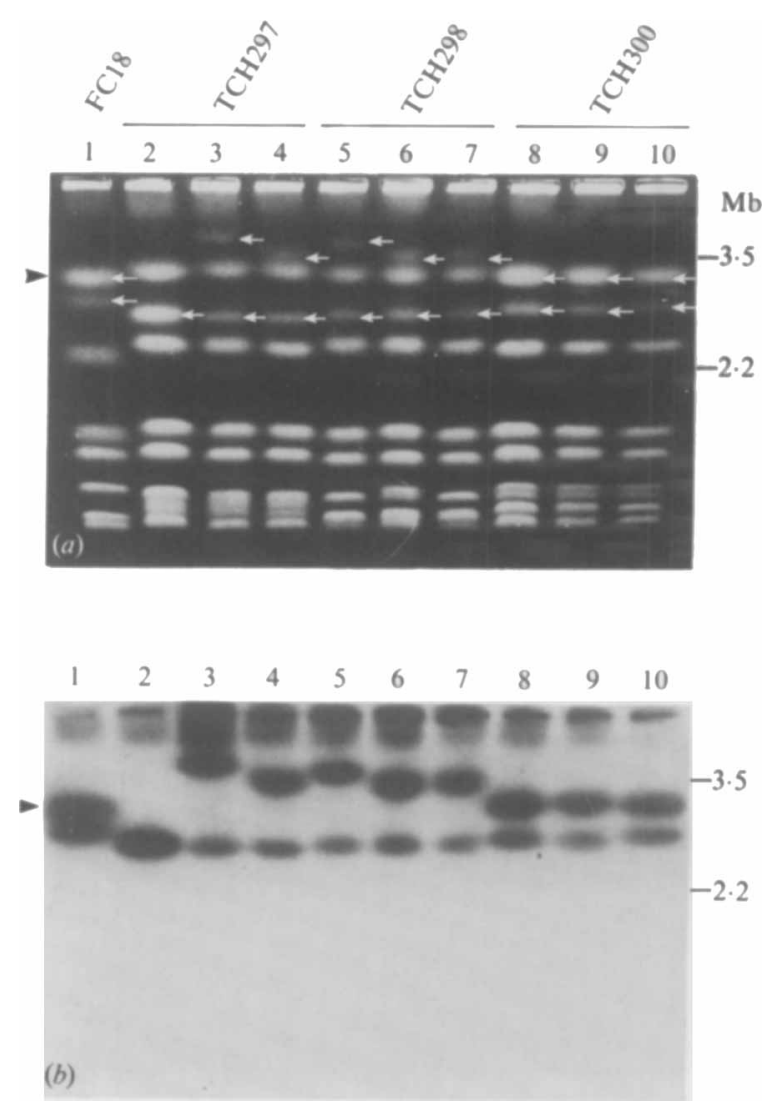

Fig. I. Size variation of chromosome 2 bands of parental clones. (a) Electrophoretic karyotypes of the parental clones isolated from three strains, TCH297, TCH298 and TCH300 (lanes 2-10) and C. albicans standard strain FC18 (lane 1). Arrows at the right of each lane indicate the bands which hybridized to rDNA in (b). (b) rDNA hybridization profile of the chromosome 2 band(s) of each clone shown in $(a)$. Arrowheads indicate the largest band of FC18. Numbers on the right margin indicate the size of the $S$. cerevisiae and Sch. pombe marker DNAs.

For this purpose, we attempted a survey using a restriction enzyme which had no recognition site within the rDNA repeat unit and which cut out the rDNA cluster region. PFGE sample plugs of strain FC18 were treated with 15 restriction enzymes having 5-, 6- or 8base recognition sequences and the rDNA fragments were detected by hybridization. Amongst them, HindIII and $X h o I$ cut out the rDNA cluster. However, a HindIII site was present in the rDNA repeat unit of some, but not all, strains used. Therefore, Xhol was used for digestion. After separation by PFGE and assigning by the rDNA probe, two large $X h o I$ fragments were detected in the range of $130-1530 \mathrm{~kb}$ in each clone (Fig. 3 and Table 2), and were thought to be derived from each of the homologues. Most of the size differences between the $X h o I$ fragments corresponded to those between the intact chromosome 2 bands in each strain (Table 2). Although chromosome 2 of clone TCH297-1 was separated as a 

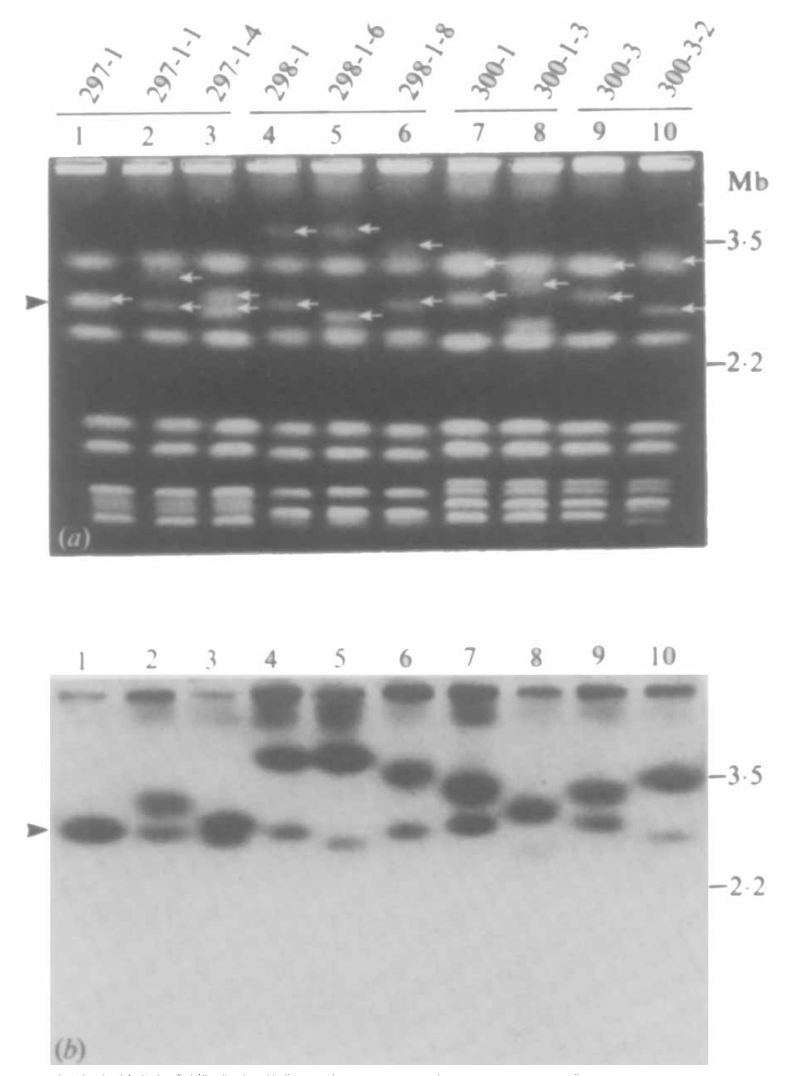

Fig. 2. Size variation of chromosome 2 bands of progeny clones. (a) Electrophoretic karyotypes of progeny clones which had different karyotypes from their parental clones. The clones are defined as follows: for example, 297-1 is a parental clone of TCH297 and both 297-1-1 and 297-1-4 are progeny clones derived from 297-1 (lanes 1-3). Arrows at the right of each lane indicate the bands which hybridized to rDNA in (b). (b) rDNA hybridization profile of the chromosome 2 band(s) of each clone shown in (a). Arrowheads indicate chromosome 2 bands of TCH297-1. Numbers on the right margin indicate the size of the $S$. cerevisiae and $S c h$. pombe marker DNAs.

single band by PFGE, two fragments of 500 and $370 \mathrm{~kb}$ were detected as a rDNA cluster in a XhoI digest. This suggested that the size of the region, except for the rDNA cluster, was different between homologues in strain TCH297. A part of the non-rDNA region was also demonstrated to be different in size between the homologues (Fig. 4).

Assuming that the intensity of the hybridization signal of the rDNA probe is correlated with the number of rDNA repeat units, the intensity of the rDNA hybridization signal of $X$ hoI fragments in Fig. 3 was measured by a BAS2000 image analyser system. To normalize total DNA content in each lane, the intensity of the hybridization signal of the LYS2 probe was measured as a reference. The relative intensity of the $X$ hoI fragment assigned by the rDNA probe is shown in Table 2 . The rDNA hybridization signal intensity roughly corresponds to the size of the XhoI rDNA fragment.

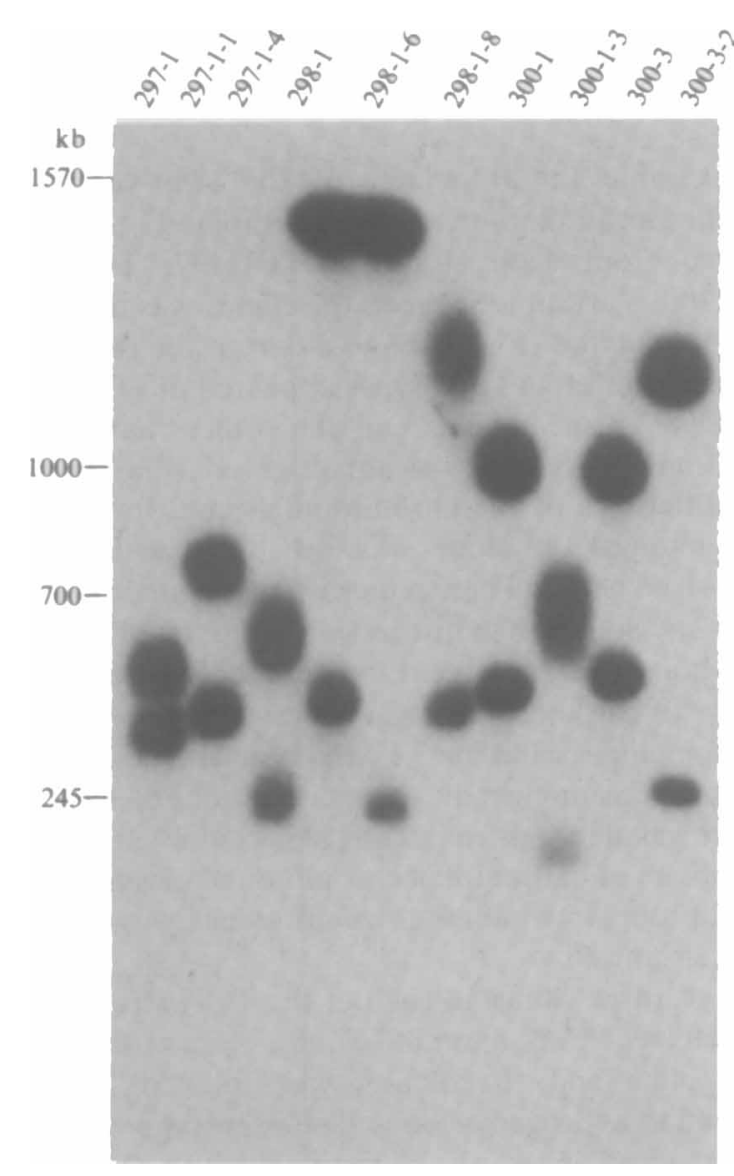

Fig. 3. XhoI fragments derived from rDNA cluster regions. PFGE sample plugs of each clone of TCH strains shown in Fig. $2(a)$ were digested with XhoI. After PFGE with a 100 s switch time at $180 \mathrm{~V}$ for $15 \mathrm{~h}$ followed by a $300 \mathrm{~s}$ switch time at $140 \mathrm{~V}$ for $20 \mathrm{~h}$ Southern hybridization using a rDNA probe was performed. The lanes correspond to those in Fig. 2(a). The estimated size of XhoI fragments in each clone is indicated in Table 2. Numbers on the left margin indicate the size of the $S$. cerevisiae marker DNAs.

\section{The size change of the non-rDNA regions}

It was suggested that the clonal size variation of chromosome 2 was due to the size change of the rDNA cluster. To confirm this, the size of non-rDNA regions was estimated in chromosome 2. As the NotI 8-base recognition sequence is rare, the NotI digestion generates large-sized fragments of the chromosome. Fortunately, NotI has only one cutting site within the rDNA gene of the repeating units. This makes it possible to detect size changes of the non-rDNA fragments.

A chromosome 2 band was cut out from a PFGE gel and the homologues were named $a$ and $b$ according to their size. After the chromosome 2 band was treated with NotI and separated again by PFGE, the fragments were detected by Southern hybridization using a chromosome 2 probe (Fig. 4). The bands between 15 and $160 \mathrm{~kb}$ 
Table 2. Size of rDNA region on chromosome 2 band(s) in TCH strains

\begin{tabular}{|c|c|c|c|c|c|c|}
\hline \multirow[b]{2}{*}{$\begin{array}{l}\text { Clones } \\
(\mathrm{TCH})^{*}\end{array}$} & \multirow{2}{*}{$\begin{array}{l}\text { Intact } \\
\text { chromosome } \\
\text { size }(\mathbf{k b})\end{array}$} & \multirow{2}{*}{$\begin{array}{c}\text { Size of } \\
\text { Xhol fragments } \\
\text { of rDNA cluster } \\
(\mathrm{kb}) \dagger\end{array}$} & \multicolumn{2}{|c|}{$\begin{array}{l}\text { Size of NotI fragments of } \\
\text { chromosome } 2(\mathrm{~kb})\end{array}$} & \multirow{2}{*}{$\begin{array}{c}\text { Relative } \\
\text { density } \\
\text { of rDNA\| }\end{array}$} & \multirow{2}{*}{$\begin{array}{l}\text { No. of } \\
\text { rDNA repeat units } \\
\text { per chromosome }\end{array}$} \\
\hline & & & $\begin{array}{l}\text { Non-rDNA } \\
\text { region } \ddagger\end{array}$ & rDNA cluster§ & & \\
\hline $297-1$ & 3100 & 370,500 & 2640,2560 & 460,540 & $0.85,1.00$ & 25,33 \\
\hline $297-1-1 \mathrm{a}$ & 3380 & 740 & 2640 & 740 & 1.09 & 49 \\
\hline $297-1-1 b$ & 3080 & 410 & 2560 & 520 & 0.71 & 27 \\
\hline $297-1-4 a$ & 3180 & 570 & 2560 & 620 & 0.96 & 38 \\
\hline $297-1-4 b$ & 2960 & 210 & 2640 & 320 & 0.47 & 14 \\
\hline $298-1 \mathrm{a}$ & 4350 & 1530 & 2580 & 1770 & 1.88 & 102 \\
\hline $298-1 b$ & 3080 & 420 & 2620 & 460 & 0.72 & 28 \\
\hline 298-1-6a & 4350 & 1530 & 2580 & 1770 & 1.99 & 102 \\
\hline $298-1-6 b$ & 2880 & 197 & 2620 & 260 & 0.39 & 13 \\
\hline $298-1-8 a$ & 3940 & 1230 & 2580 & 1360 & 1.44 & 82 \\
\hline $298-1-8 b$ & 3080 & 420 & 2620 & 460 & 0.71 & 28 \\
\hline $300-1 a$ & 3500 & 1000 & 2540 & 960 & 1.70 & 67 \\
\hline $300-1 b$ & 3100 & 480 & 2650 & 450 & 0.89 & 32 \\
\hline $300-1-3 a$ & 3280 & 640 & 2650 & 630 & 1.25 & 43 \\
\hline $300-1-3 b$ & 2700 & 130 & 2540 & 160 & 0.24 & 9 \\
\hline $300-3 a$ & 3580 & 1000 & 2560 & 1020 & 1.71 & 67 \\
\hline $300-3 b$ & 3120 & 500 & 2660 & 460 & 0.82 & 33 \\
\hline $300-3-2 a$ & 3750 & 1200 & 2560 & 1190 & 1.96 & 80 \\
\hline $300-3-2 b$ & 2960 & 240 & 2660 & 300 & 0.47 & 16 \\
\hline
\end{tabular}

* The larger of the two homologues of chromosome 2 is designated as 'a', the smaller homologue as ' $b$ '.

$\dagger$ The size of the XhoI fragments was assigned by a rDNA probe as shown in Fig. 3.

$\ddagger$ Total size of NotI fragments in each chromosome 2 band, except for the rDNA region.

$\S$ The size of the rDNA cluster was calculated by subtracting the total size of the non-rDNA region Notl fragments from the intact size of the corresponding chromosome 2.

$\|$ The density of rDNA hybridization to Xhol fragments in Fig. 3 was measured using a BAS2000 image analyser. The DNA content in each lane was normalized with the density of LYS2 hybridization.

I The number of rDNA repeat units was calculated by dividing the size of the rDNA fragment produced by Xhol digestion by the size of the rDNA repeat cluster NotI fragment $(15 \mathrm{~kb})$.

(indicated by bracket $A$ in Fig. 4) were recognized by the rDNA probe but were not detected reproducibly (Fig. 5). They seem to be partially digested fragments of rDNA. These were not detected after longer incubation with the enzyme, although other fragments did not change in size and hybridized intensively. The $420 \mathrm{~kb}$ fragment seen in 300-1a and 300-3a (Fig. 4, lanes 12 and 16) seem to be derived from the chromosome 1 band which comigrated with chromosome 2 on the PFGE gel, because this fragment was also recognized by a chromosome 1 probe (data not shown). Chromosome 1 has some homology to chromosome 2 (unpublished data). Thus, the $420 \mathrm{~kb}$ fragments probably contain the region homologous to chromosome 2 . The smallest bands had a very strong signal (Fig. 4) and were also found by the rDNA probe (Fig. 5). This suggests that the bands correspond to the repeating unit derived from the rDNA cluster. The size of the repeating unit was shown to be strain-specific; 14.3 and $15 \mathrm{~kb}$ for TCH297, $15 \mathrm{~kb}$ for TCH298, or $15.2 \mathrm{~kb}$ for TCH 300 (Fig. 6). However, the size of the rDNA repeat unit was not changed amongst the clones of each strain. The $260 \mathrm{~kb}$ fragment was also recognized by the rDNA probe, although the intensity of the hybridization signal was low, similar to that seen with the MGL1 probe (Fig. 5). This is thought to be caused by the fragments adjacent to the rDNA cluster which contain a part of the rDNA repeat unit.

Four large NotI fragments of a non-rDNA region were detected in each chromosome 2 band except for 297-1, whose homologues were not separated on the gel (Fig. 2). The homologues of 297-1 gave five fragments of 160,260 , 790,870 and $1350 \mathrm{~kb}$, though the 790 and $870 \mathrm{~kb}$ fragments were not adequately separated (Fig. 4, lane 1), but either the $790 \mathrm{~kb}$ or the $870 \mathrm{~kb}$ fragment was found in the separated homologue of chromosome 2 from the progeny clones (Fig. 4, lanes 2-5). The fragments of nonrDNA did not appear to change between the parental and progeny clones in each strain. In addition, we calculated the size of the rDNA cluster in each chromosome 2 band by subtracting the total size of the non-rDNA fragments from the length of intact chromosome 2 estimated by PFGE (Table 2). In all the 


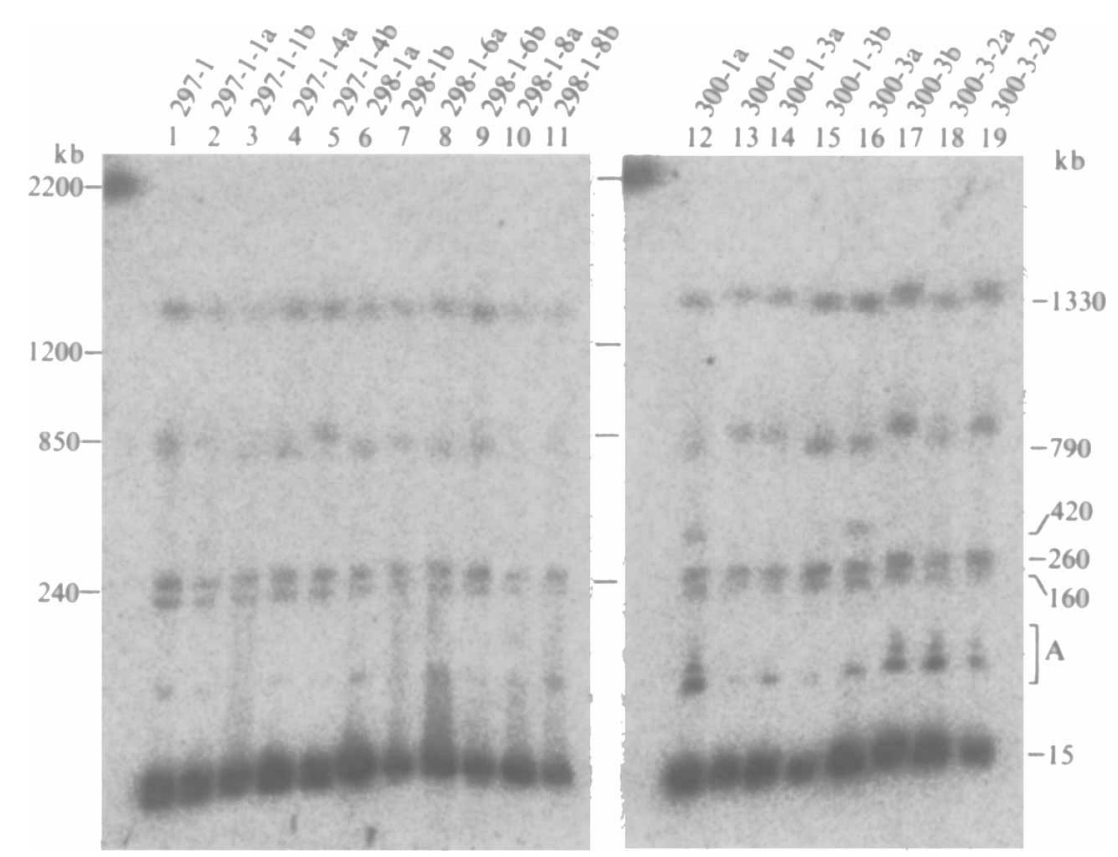

Fig. 4. NotI fragments of chromosome 2 band(s) detected by Southern hybridization using a chromosome 2 DNA probe. Chromosome 2 band(s) of each clone shown in Fig. 2 were cut out from a PFGE gel, digested with $N o t \mathrm{I}$ and separated again by PFGE under the conditions described in the legend to Fig. 3. The larger homologue was referred to as ' $a$ ' and the smaller one as ' $b$ '. The smallest band in each lane corresponded with the rDNA repeat unit. Numbers on the right margin indicate the NotI fragment size of the larger chromosome 2 band in $\mathrm{TCH} 300-3$ (300-3a). Bracket A indicates bands caused by incomplete digestion (see $\mathrm{Re}$ sults). Numbers on the left margin indicate the size of the $S$. cerevisiae marker DNAs.

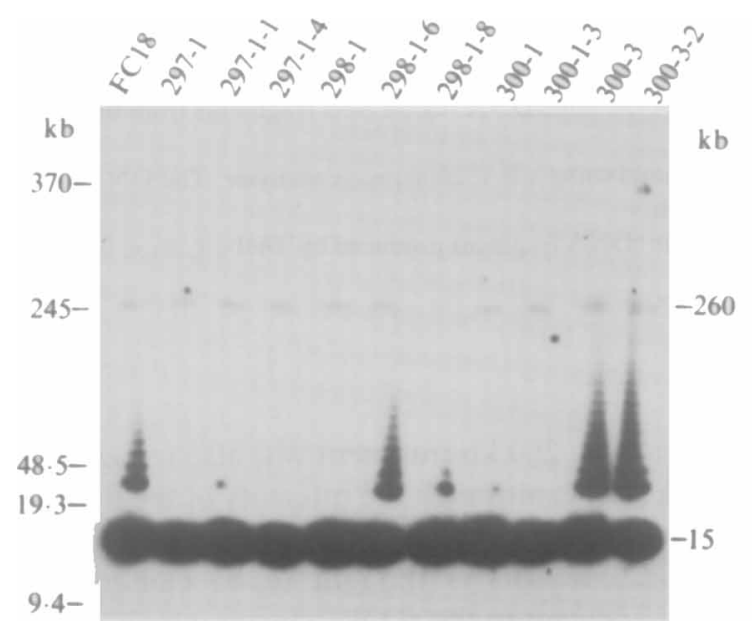

Fig. 5. rDNA hybridization profile of NotI fragments. PFGE sample plugs of each clone of the TCH strains shown in Fig. 2(a) were digested with NotI. After PFGE with a ramping switch time from 20 to $40 \mathrm{~s}$ at $200 \mathrm{~V}$ for $18 \mathrm{~h}$ in $1 \%$ agarose gel, Southern hybridization using a rDNA probe was carried out. The lanes correspond to those in Fig. 2(a). Numbers on the left margin indicate the size markers of the $\lambda$ concatemer ladder and of $\lambda$ DNA digested with EcoT14I. Numbers on the right margin indicate the size of the NotI fragments estimated from the size markers.

chromosome 2 bands, the calculated size was in reasonable agreement with the size of the XhoI-digested fragment assigned as the rDNA region.

These data supported the concept that the size change of chromosome 2 occurs in the rDNA cluster and not in the non-rDNA region.
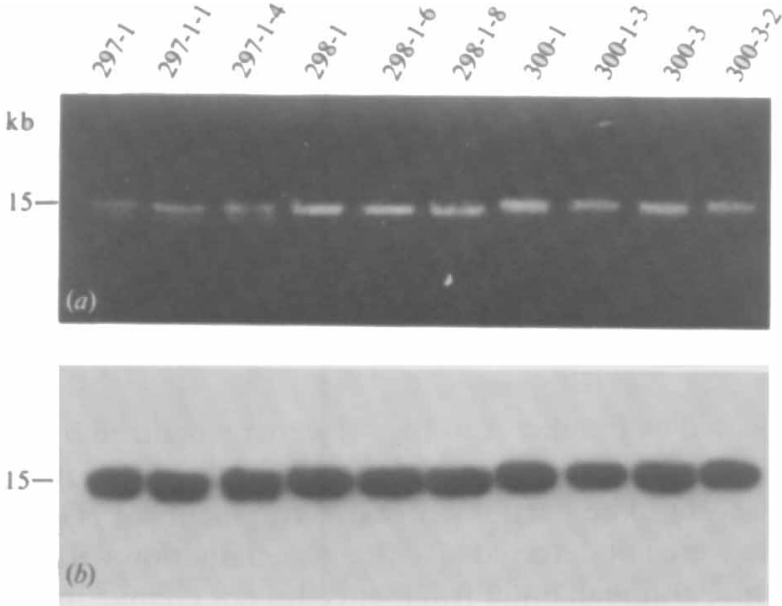

Fig. 6. rDNA repeat unit. After samples were prepared and the DNA fragments were separated by PFGE as described in the legend to Fig. 5, the gel was stained with ethidium bromide $(a)$, and Southern hybridization using a rDNA probe was carried out $(b)$. Numbers on the left margin indicate the estimated size of the larger band of the rDNA repeat unit of $\mathrm{TCH} 297-1$.

\section{Discussion}

The remarkable variation in the size of chromosome 2 (alternatively called chromosome $\mathbf{R}$ or chromosome VIII), which carries a rDNA gene, has been observed in stock strains (Iwaguchi et al., 1990; Wickes et al., 1991), clinical isolates (Asakura et al., 1991), and morphological mutants (Rustchenko-Bulgac, 1991). When we analysed 
multiple clones derived from a common ancestor, we found that clonal change of electrophoretic karyotype is detectable with a frequency of variation greater than $10 \%$ for chromosome 2 of the progeny clones. It has been assumed that the rDNA gene sequence is usually highly repeated in a single region, DNA rearrangement occurs at high frequency in the region, and such rearrangements may be responsible for the change in chromosome size. We confirmed the assumption that the clonal size change of chromosome 2 is derived from the size change of the rDNA cluster from the following lines of evidence. (i) The size change of the rDNA fragment produced by $X h o I$, whose recognition site was not present in the rDNA repeat unit, corresponded to the size change of the intact chromosome 2. (ii) The hybridization intensity of rDNA correlated to the size of the rDNA fragment. (iii) The non-rDNA fragments of chromosome 2 produced by NotI, which had a single recognition site in the rDNA repeat unit, did not change in the progeny clones of each strain. (iv) The calculated size of the rDNA cluster of chromosome 2 , which was obtained by subtracting the total size of the non-rDNA NotI fragments from the intact size of chromosome 2, corresponded to the size of the rDNA XhoI fragment. (v) The size of the rDNA repeat unit was not altered in the clones of each strain.

The number of rDNA repeat units for each chromosome 2 can be estimated by dividing the size of the rDNA $X h o I$ fragment by the size of the rDNA repeat unit. When we take $15 \mathrm{~kb}$ as the rDNA repeat unit size, the number of rDNA repeating units per homologue of chromosome 2 varies from about 9 to about 100 and the number per cell varies from about 50 to about 130 (Table 2). Compared to the parental clone, the number tended to decrease in the progeny clones. It has usually been believed that the rDNA cluster size is relatively stable in vegetative growth. A haploid strain of $S$. cerevisiae has about 140 copies of the rDNA repeat unit (Cramer $e t$ al., 1972) and this number is thought to be maintained by unequal crossing-over events during mitotic growth (Stark \& Wahl, 1984; Szostak \& Wu, 1980). A similar maintenance mechanism for the rDNA number is observed in Neurospora crassa (Rodland \& Russell, 1982, 1983; Russell \& Rodland, 1986).

It has been shown that mitotic recombination in the rDNA cluster of $S$. cerevisiae is suppressed by the combined action of topoisomerase I and topoisomerase II (Christman et al., 1988) or suppressed by the function of a transcriptional silencer gene, SIR2 (Gottlieb \& Esposito, 1989). It has been reported that a mitotic recombination hot spot, namely HOT1, is located in the rDNA repeat unit (Keil \& Roeder, 1984). Recombination in the rDNA cluster in C. albicans may involve homologous factors.

It has been roughly estimated that the rate of marker loss in the rDNA region of $S$. cerevisiae is $5 \times 10^{-4}$ per cell division (Szostak \& Wu, 1980). Therefore the frequency of unequal crossing-over within the whole rDNA region is $10^{-2}$ per cell division, based on the value of 140 repeat units of the rDNA cluster of $S$. cerevisiae. The frequency of detectable size change of the rDNA region of $C$. albicans was estimated to be about $5 \times 10^{-3}$ per cell division. It would appear that the high frequency change observed in C. albicans cannot be solely attributable to unequal crossing-over (Petes \& Hill, 1988), although it is obviously difficult to compare rates based on different experimental approaches.

The bobbed mutants of Drosophila melanogaster with partial deletions of rDNA show abnormal phenotypes, such as shorter bristle and slow development as well as other pleiotropic effects (Hawley \& Marcus, 1989; Tartof, 1974). We originally suspected that the size change of the rDNA cluster might result in a phenotypic change such as a change in colony morphology which had been reported to be associated with karyotypic change (Rustchenko-Bulgac et al., 1990; Suzuki et al., 1989). However, no detectable phenotypic change was observed in clones carrying the size change in the rDNA cluster. The minimal number of rDNA units per cell was estimated to be 50 copies in the clones (Table 2). This number may be sufficient to ensure its correct function in C. albicans.

We thank J. A. Gorman (Squibb), B. B. Magee (University of Minnesota, USA) and A. Toh-e (University of Tokyo, Japan) for gifts of the plasmids used as probes, and K. Higashide (Chita City Hospital, Japan) for the TCH strains. We would also like to thank Timothy J. Lott for critical reading of the manuscript.

\section{References}

Asakura, K., Iwaguchi, S.-I., Homma, M., Sukai, T., Higashide, K. \& TANAKA, K. (1991). Electrophoretic karyotypes of clinically isolated yeasts of Candida albicans and C. glabrata. Journal of General Microbiology 137, 2531-2538.

Buesching, W. J., KureK, K. \& RoberTs, G. D. (1979). Evaluation of the modified API $20 \mathrm{C}$ system for identification of clinically important yeasts. Journal of Clinical Microbiology 9, 565-569.

Christman, M. F., Dietrich, F. S. \& Fink, G. R. (1988). Mitotic recombination in the rDNA of $S$. cerevisiae is suppressed by the combined action of DNA topoisomerases I and II. Cell 55, 413-425.

Chu, G., Vollrath, D. \& Davis, R. W. (1986). Separation of large DNA molecules by contour-clamped homogeneous electric fields. Science 234, 1582-1585.

Corcoran, L. M., Thompson, J. K. \& Kemp, D. J. (1988). Homologous recombination within subtelomeric repeat sequences generates chromosome size polymorphism in $P$. falciparum. Cell 53, 807-813.

Cramer, J. H., Bhargava, M. M. \& Halvorson, H. O. (1972). Isolation and characterization of $\gamma$ DNA of Saccharomyces cerevisiae. Journal of Molecular Biology 71, 11-20.

Fan, J.-B., Chikashige, Y., Smith, C. L., Niwa, O., Yanagida, M. \& CANTOR, C. R. (1988). Construction of a Not I restriction map of the fission yeast Schizosaccharomyces pombe genome. Nucleic Acids Research 17, 2801-2818. 
GotTlieb, S. \& Esposito, R. E. (1989). A new role for a yeast transcriptional silencer gene, SIR2, in regulation of recombination in ribosomal DNA. Cell 56, 771-776.

HAWLEY, R. S. \& MARCUS, C. H. (1989). Recombinational controls of rDNA redundancy in Drosophila. Annual Review of Genetics 23, 87120.

IwaGUChI, S.-I., Homma, M. \& TANaKA, K. (1990). Variation in the electrophoretic karyotype analysed by the assignment of DNA probes in Candida albicans. Journal of General Microbiology 136, 2433-2442.

KEIL, R. L. \& RoEder, G. S. (1984). Cis-acting, recombinationstimulating activity in a fragment of the ribosomal DNA of $S$. cerevisiae. Cell 39, 377-386.

Lasker, B. A., Carle, G. F., Kobayashi, G. S. \& Medoff, G. (1989). Comparison of the separation of Candida albicans chromosome-sized DNA by pulsed-field gel electrophoresis techniques. Nucleic Acids Research 17, 3783-3793.

LoTT, T. J., BoIron, P. \& Reiss, E. (1987). An electrophoretic karyotype for Candida albicans reveals large chromosomes in multiples. Molecular and General Genetics 209, 170-174.

Magee, B. B., Koltin, Y., Gorman, J. A. \& Magee, P. T. (1988). Assignment of cloned genes to the seven electrophoretically separated Candida albicans chromosomes. Molecular and Cellular Biology 8, 4721-4726.

Merz, W. G. (1990). Candida albicans strain delineation. Clinical Microbiology Reviews 3, 321-334.

Merz, W. G., Connelly, C. \& Hieter, P. (1988). Variation of electrophoretic karyotypes among clinical isolates of Candida albicans. Journal of Clinical Microbiology 26, 842-845.

MORTIMER, R. K. \& SCHILD, D. (1985). Genetic map of Saccharomyces cerevisiae, edition 9. Microbiological Reviews 49, 181-212.

ODDs, F. C. (1988). Candida and Candidosis, 2nd edn. London: Bailliere Tindall.

Petes, T. D. \& Hill, C. W. (1988). Recombination between repeated genes in microorganisms. Annual Review of Genetics 22, 147-168.

Poulter, R., Jeffery, H., Hubbard, M. J., ShePherd, M. G. \& Sullivan, P. A. (1981). Parasexual genetic analysis of Candida albicans by spheroplast fusion. Journal of Bacteriology 146, 833840.

Riggsby, W. S., Torres-Bauza, L. J., Wills, J. W. \& Townes, T. M. (1982). DNA content, kinetic complexity, and the ploidy question in Candida albicans. Molecular and Cellular Biology 2, 853-862.

Rodland, K. D. \& Russell, P. J. (1982). Regulation of ribosomal RNA cistron number in a strain of Neurospora crassa with a duplication of the nucleolus organizer region. Biochimica et Biophysica Acta 697, 162-169.
Rodland, K. D. \& Russell, P. J. (1983). Segregation of heterogeneous rDNA segments during demagnification of a Neurospora crassa strain possessing a double nucleolar organizer. Current Genetics 7 , 379-384.

Russell, P. J. \& Rodland, K. D. (1986). Magnification of rRNA gene number in a Neurospora crassa strain with a partial deletion of the nucleolus organizer. Chromosoma 93, 337-340.

RUSTCHENKo-BULGAC, E. P. (1991). Variations of Candida albicans electrophoretic karyotypes. Journal of Bacteriology 173, 6586-6596.

Rustchenko-Bulgac, E. P., Sherman, F. \& Hicks, J. B. (1990) Chromosomal rearrangements associated with morphological mutants provide a means for genetic variation of Candida albicans. Journal of Bacteriology 172, 1276-1283.

SCHERER, S. \& MAGEe, P. T. (1990). Genetics of Candida albicans Microbiological Reviews 54, 226-241.

ShapIRo, J. A. (1983). Mobile Genetic Elements. London: Academic Press.

Shinoda, T., Kaufman, L. \& Padhye, A. A. (1981). Comparative evaluation of the Iatron serological candida check kit and the API 20 C kit for identification of medically important Candida species. Journal of Clinical Microbiology 13, 513-518.

SNell, R. G., Hermans, I. F., Wilkins, R. J. \& CoRner, B. E. (1987). Chromosomal variation in Candida albicans. Nucleic Acids Research 15,3625 .

StaRK, G. R. \& WAHL, G. M. (1984). Gene amplification. Annual Review of Biochemistry 53, 447-491.

Sugihara, K., OHISHI, K. \& Toh-E, A. (1986). Ribosomal DNA plasmid isolated from Zygosaccharomyces bailii and its use for constructing yeast vectors effective for intergeneric gene transfer. Agricultural and Biological Chemistry 50, 1503-1512.

Suzuki, T., Kobayashi, I., Kanbe, T. \& Tanaka, K. (1989). High frequency variation of colony morphology and chromosome reorganization in the pathogenic yeast Candida albicans. Journal of General Microbiology 135, 425-434.

Szostak, J. W. \& Wu, R. (1980). Unequal crossing over in the ribosomal DNA of Saccharomyces cerevisiae. Nature, London 284, 426-430.

TARTOF, K. D. (1974). Unequal mitotic sister chromatid exchange as the mechanism of ribosomal RNA gene magnification. Proceedings of the National Academy of Sciences of the United States of America 71, 1272-1276.

Wickes, B., Staudinger, J., Magee, B. B., Kwon-Chung, K.-J., MAGEE, P. T. \& SChERER, S. (1991). Physical and genetic mapping of Candida albicans: several genes previously assigned to chromosome 1 map to chromosome $R$, the rDNA-containing linkage group. Infection and Immunity 59, 2480-2484. 